\title{
Editorial
}

\section{Primer año cumplido y en camino a la indexación}

First year completed and on the way to indexation

Manuel Chacón Diaz ${ }^{11, a}$

Recibido: 21 de marzo 2021 Aceptado: 23 de marzo de 202

Filiación

Instituto Nacional Cardiovascula (INCOR), EsSalud. Lima, Perú.

Médico cardiólogo. Editor general

APCyCCV.

\section{Correspondencia}

Coronel Zegarra 417, Jesús María Lima, Perú.

Correo

manuelchacon03@yahoo.es

Conflicto de interes

Ninguno

Financiamiento

Autofinanciado.

Citar como:

Chacón-Diaz M. Primer año cumplido y en camino a la indexación [editorial]. Arch Peru Cardiol Cir Cardiovasc 2021;2(1):1-2. doi: 10.47487/apcyccv. v2i1.129
Hace un año que comenzó la publicación trimestral de APCyCCV, en busca de obtener un espacio adecuado para dar a conocer nuestras experiencias científicas en investigación original, casos clínicos y revisiones de temas sobre patología cardiovascular. Luego de cuatro números publicados, podemos decir que ha sido una experiencia gratificante para el Consejo Editorial de la revista, ya que hemos podido apreciar el cálido recibimiento de los artículos no solo por nuestros lectores nacionales, sino también por la gran comunidad científica a nivel internacional.

Hoy podemos decir que el camino a lograr la ansiada indexación esta ya trazado y lo estamos atravesando de manera segura y con la participación de un gran grupo editorial comprometido con desarrollar la revista siguiendo altos estandares de calidad. Este año con la renovación del consejo editorial, hemos querido incluir a profesionales con experiencia en investigación y publicación científica nacionales e internacionales con quienes tenemos el firme propósito de hacer de APCYCCV la revista médica más importante en el país y un medio de consulta importante a nivel latinoamericano.

En este primer año, hemos logrado ingresar al directorio de Latindex, tener acceso a nuestros artículos a través del buscador Google Académico y estar indexado en el directorio DOAJ (Directory of Open Access Journals) y vamos en camino a indexar a SciELO durante este segundo año y postular a SCOPUS y Medline entre otras bases de datos para el 2022 (Figura 1).

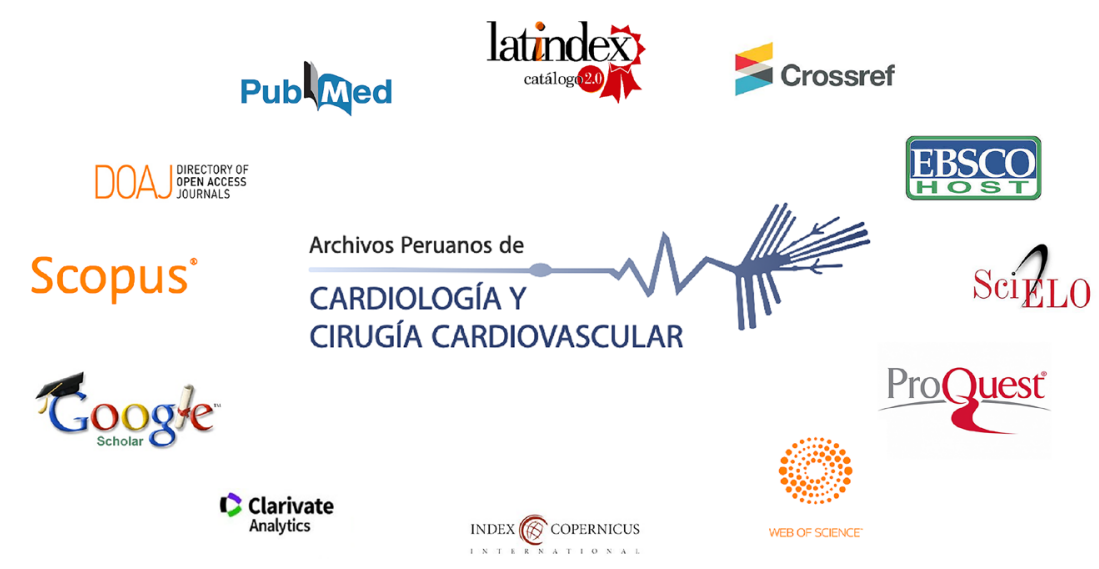

Figura 1. Metas de indexación de APCyCCV para el periodo 2021-2022 
Pero nada de lo logrado, y por lograr, hubiera sido posible sin la confianza de los autores en publicar sus investigaciones con nosotros. Profesionales de primer nivel nacionales e internacionales han visto en esta revista la opción de dar a conocer sus manuscritos a quienes agradecemos profundamente por su participación; asi como también, a nuestros revisores que haciendo un espacio a su labor diaria han hecho que cada artículo publicado logre los estándares exigidos gracias a la experiencia en sus respectivas áreas de conocimiento científico.

La evolución en las publicaciones científicas, el hacerlas cada vez más cercanas a los lectores y los requerimientos de indexación, nos recomiendan desde este segundo año alinearnos a las prácticas de comunicación de la ciencia abierta, a través de las cuales no solo se garantiza el acceso abierto a nuestros contenidos, sino también permite la apertura al proceso editorial por la cual los autores pueden conocer a los revisores e interactuar entre ellos para la mejora de su manuscrito, retirando, si así lo desean, la premisa del doble ciego; permite, también, el uso de preprints como parte inicial de la producción de un artículo y el acceso a los materiales subyacentes a la producción de los artículos. Por lo anterior, desde este número se solicitara a los autores el envío del formulario de conformidad con la ciencia abierta (el cual está disponible en: https://wp.scielo.org/ wp-content/uploads/Formulario-sobre-Conformidad-con-laCiencia-Abierta_es.docx), junto con el envío de su manuscrito.

Un objetivo para nuestras futuras publicaciones, es promover el envío del «resumen visual» de los artículos originales y de revisión, a través de la creación de la figura central del artículo, haciendo que el lector pueda apreciar con mayor facilidad las caracteristicas del artículo respectivo y pueda compartirse fácilmente por intermedio de la web y redes sociales.

Como nuestro compromiso es seguir creciendo y manteniendo la calidad de nuestras publicaciones, en este número tenemos el gran honor de contar con los profesores Antoni Bayés de Luna, Adrián Baranchuk, Manuel Martinez y
Roberto Elosua quienes, junto al doctor Pablo lomini, presentan una brillante revisión que ningún cardiólogo deberia dejar de leer, en su artículo titulado: "Síndrome de Bayés, accidente cerebrovascular y demencia» nos presentan detalladamente la fisiopatología y evidencia científica, hasta la fecha, de la asociación entre el bloqueo interauricular avanzado, el deterioro cognitivo y los eventos isquémicos cerebrales.

Completamos los artículos de revisión con el tema «Revascularización miocárdica en la disfunción ventricular izquierda», donde A. Godoy presenta un resumen de la evidencia del beneficio (o no) de revascularizar pacientes con insuficiencia cardiaca con fracción de eyección disminuida y del uso de las técnicas de imágenes para evidenciar viabilidad miocárdica en este grupo de pacientes. Además, L. Melgar et al., desarrollan una excelente revisión sobre la importancia del «Síndrome de QT largo congénito» en los episodios de arritmia ventricular y muerte súbita en la población pediátrica.

Huerta et al., presentan una serie de casos en su artículo. «Perfil clínico y estrategias terapéuticas en pacientes con miocardiopatía arritmogénica tratados en un Instituto de referencia nacional», donde trece pacientes estudiados nos permiten conocer las características de presentación, métodos diagnósticos y tratamiento de esta enfermedad en nuestra localidad. Carhuallanqui et al., nos presentan un interesante artículo original «Fragilidad en adultos mayores con falla cardiaca crónica en un hospital de Lima» donde evaluan la fragilidad del paciente con insuficiencia cardiaca y la implicancia que esta tiene en los desenlaces de estas personas. Por último, Espinoza et al., analizan el "Efecto de un programa de entrenamiento físico en la ocurrencia de arritmias inducidas por el ejercicio en pacientes con cardiopatía» en un interesante artículo original desde México.

Los miembros del equipo editorial de Archivos Peruanos de Cardiología y Cirugía Cardiovascular, esperamos que los artículos de este número sean de su interés. 